This article was published in Progress in Neuro-

Psychopharmacology \& Biological Psychiatry, 99, Janine Weibel;

Yu-Shiuan Lin; Hans-Peter Landolt; Corrado Garbazza; Vitaliy Kolodyazhniy; Joshua Kistler; Sophia Rehm; Katharina Rentsch;

Stefan Borgwardt; Christian Cajochen; Carolin Reichert, Caffeinedependent changes of sleep-wake regulation: Evidence for adaptation after repeated intake, Copyright Elsevier (2019).

CC-BY-NC-ND license 


\section{Caffeine-dependent changes of sleep-wake regulation: evidence for adaptation after repeated intake}

Janine Weibel ${ }^{1,2}$, Yu-Shiuan Lin ${ }^{1,2,3}$, Hans-Peter Landolt ${ }^{4,5}$, Corrado Garbazza ${ }^{1,2}$, Vitaliy Kolodyazhniy ${ }^{6}$, Joshua Kistler ${ }^{1,2}$, Sophia Rehm ${ }^{7}$, Katharina Rentsch ${ }^{7}$, Stefan Borgwardt ${ }^{3}$, Christian Cajochen ${ }^{1,2^{*}}$ and Carolin Reichert ${ }^{1,2^{*}}$

1 Centre for Chronobiology, Psychiatric Hospital of the University of Basel, Basel, Switzerland

2 Transfaculty Research Platform Molecular and Cognitive Neurosciences, University of Basel, Basel, Switzerland

${ }^{3}$ Neuropsychiatry and Brain Imaging, Psychiatric Hospital of the University of Basel, Basel, Switzerland

${ }^{4}$ Institute of Pharmacology and Toxicology, University of Zürich, Zürich, Switzerland

${ }^{5}$ Sleep \& Health Zürich, University Center of Competence, University of Zürich, Zürich, Switzerland

${ }^{6}$ F. Hoffmann-La Roche Ltd, Basel, Switzerland

7 Laboratory Medicine, University Hospital Basel, Basel, Switzerland

*Authors contributed equally to this work

\section{Corresponding author:}

Christian Cajochen, Centre for Chronobiology, Psychiatric Hospital of the University of Basel, Wilhelm Klein-Strasse 27, 4002 Basel, Switzerland.

Email: christian.cajochen@upk.ch 


\section{Abstract}

Background: Circadian and sleep-homeostatic mechanisms regulate timing and quality of wakefulness. To enhance wakefulness, daily consumption of caffeine in the morning and afternoon is highly common. However, the effects of such a regular intake pattern on circadian sleep-wake regulation are unknown. Thus, we investigated if daily daytime caffeine intake and caffeine withdrawal affect circadian rhythms and wake-promotion in habitual consumers.

Methods: Twenty male young volunteers participated in a randomised, double-blind, withinsubject study with three conditions: i) caffeine (150 mg $3 \times$ daily for 10 days), ii) placebo ( $3 \mathrm{x}$ daily for 10 days) and iii) withdrawal (150 mg caffeine $3 \times$ daily for eight days, followed by a switch to placebo for two days). Starting on day nine of treatment, salivary melatonin and cortisol, evening nap sleep as well as sleepiness and vigilance performance throughout day and night were quantified during $43 \mathrm{~h}$ in an in-laboratory, light and posture-controlled protocol.

Results: Neither the time course of melatonin (i.e. onset, amplitude or area under the curve) nor the time course of cortisol was significantly affected by caffeine or withdrawal. During withdrawal, however, volunteers reported increased sleepiness, showed more attentional lapses as well as polysomnography-derived markers of elevated sleep propensity in the late evening compared to both placebo and caffeine conditions.

Conclusions: The typical pattern of caffeine intake with consumption in both the morning and afternoon hours may not necessarily result in a circadian phase shift in the evening nor lead to clear-cut benefits in alertness. The time-of-day independent effects of caffeine withdrawal on evening nap sleep, sleepiness and performance suggest an adaptation to the substance, presumably in the homeostatic aspect of sleep-wake regulation.

\section{Keywords}

Caffeine, withdrawal, circadian, alertness, sleep 


\section{Introduction}

Caffeine is the most commonly consumed psychoactive substance in the world [1]. Around $80 \%$ of the worldwide population consume caffeine regularly on a daily basis [2] and intake is increasing in terms of daily dosages and earlier age of regular substance intake [3]. Caffeine containing aliments, e.g. coffee, tea, soda drinks and chocolate [1], are used since centuries to modulate sleep and wakefulness [4].

Timing, quality and quantity of sleep and wakefulness are regulated by the interplay of a homeostatic and circadian process [5]. Caffeine interferes with sleep homeostasis by antagonising adenosine receptors [6], a proposed mediator of the increase of homeostatic sleep pressure during time spent awake and its decrease during sleep [7]. By blocking the $A_{1}$ and $A_{2 A}$ adenosine receptors [1], which are expressed in wide-spread areas of the human central nervous system [8,9], acute caffeine administration reduces the effects of sleep pressure, as mirrored in reduced sleepiness [10], improved behavioural performance [11] and dampened sleep depth during nighttime sleep [6], particularly when sleep pressure is high $[3,12]$.

Furthermore, evidence accumulates that caffeine also impacts on human circadian rhythms, as indexed by changes in salivary melatonin levels following administrations at a certain circadian phase. Acute caffeine intake in the evening and at night has been shown to delay the onset of melatonin secretion [13] and decrease nighttime melatonin levels [14,15]. However, evening intake of caffeine is not common in the society nowadays [16]. Considering the average half-life of caffeine with a duration of around $4 \mathrm{~h}$ [12], the question arises whether caffeine-induced circadian effects also occur when consumption is timed to morning and afternoon, as observed in habitual caffeine consumers [16].

Besides the timing of caffeine intake, the duration of prior repeated daily use moderates the impact of caffeine-induced changes on sleep-wake regulation. There is evidence that consumers develop tolerance to the substance already after several days, such that effects of a particular dose of caffeine, for instance on sleep [17] or alertness [10] become weakened. However, in line with a recent study in animals [18], it has also been shown that continuous hourly caffeine intake over four weeks strengthens circadian wake-promotion, as indicated by a reduced ability to sleep prior to habitual bedtime [19]. Interestingly, timing of melatonin secretion 
was not shifted by the long-term treatment. An open question remains, whether the absence of phase shifts can be traced back to the continuous timing of caffeine administration around the entire circadian cycle or due to neuroadaptations in response to long-term treatment.

One of the typical indicators of neuronal and systemic alterations in response to long-term caffeine use is the occurrence of withdrawal symptoms when intake is ceased [20]. Caffeine withdrawal symptoms include decreased alertness [10,21], impaired cognitive performance $[10,21]$ and changes in waking electroencephalogram (EEG) such as enhanced theta power [22], starting 12 to $24 \mathrm{~h}$ after last caffeine intake with peak intensity between 20 to $51 \mathrm{~h}$ and a maximal duration of nine days [20]. Based on changes in adenosine-signaling [23], caffeine withdrawal thus constitutes states of low arousal which may help triggering the maintenance of daily caffeine intake in habitual consumers [20]. However, to our best knowledge the impact of caffeine-withdrawal on human circadian sleep-wake regulation has not yet been examined.

Thus, we investigated the effects of daily daytime caffeine consumption and its withdrawal on human waking performance, circadian rhythms and wake-promotion. To establish both tolerance and withdrawal, and to enable a comparison to a withdrawal-free baseline, caffeine and placebo, respectively, were administered over 10 days in a crossover design with three conditions (caffeine, placebo and withdrawal). Starting at day nine of treatment, sleepiness and vigilance performance was assessed as well as salivary melatonin, cortisol and nap sleep during high circadian wake-promotion within a 43h-laboratory protocol under controlled light, posture and meal intake.

\section{Methods}

The present study was approved by the Ethics Committee northwest/central Switzerland (EKNZ) and conducted in accordance with the declaration of Helsinki. All volunteers provided written informed consent and received a monetary compensation for study participation.

\section{Volunteers}

In total, 179 male healthy habitual caffeine consumers underwent a thorough screening procedure. Exclusion criteria comprised age $<18$ or $>35$ years, body mass index $(\mathrm{BMI})<18$ or 
$>26$, drug dependency, shiftwork within three months prior to study admission, transmeridian travels within one month prior to study, extreme chronotype (Morningness-Eveningness Questionnaire [24], score $\leq 30$ and $\geq 70$ ) and poor sleep quality (Pittsburgh Sleep Quality Index [25], score $>5$ ). Female volunteers were excluded in order to reduce variance in our data due to the menstrual cycle [26] and use of oral contraceptives [27,28]. Volunteers were included when habitual daily caffeine intake was between 300 and $600 \mathrm{mg}$, assessed with a survey tool based on [29] and adapted to the caffeine content according to [12]. Twenty-nine volunteers were invited for a habituation night and a physical examination by a physician in charge to exclude poor sleep efficiency (SE $<70 \%$ ), clinical sleep disturbances (apnea index $>10$, periodic leg movements $>15 / \mathrm{h}$ ) and chronic or debilitating medical conditions. Demographic characteristics of the 20 participants who completed all three conditions can be found in the supplementary materials (Table S1).

\section{Design and protocol}

The protocol is illustrated in Figure 1(a). A double-blind, crossover study comprising three conditions was conducted: a caffeine, a placebo and a withdrawal condition. This within-subject design was chosen to reduce variance in the data due to expectancies or inter-individual variability in caffeine metabolism. For calculation of sample size and pseudo-random allocation of volunteers to the order of the three conditions, see supplementary materials (Table S3). In each condition, participants ingested gelatin capsules over 10 days three times daily (+45 min, +255 min, +475 min after wake-up), containing either placebo (mannitol, Hänseler AG, Herisau, Switzerland) or caffeine (150 mg, Hänseler AG, Herisau, Switzerland). Participants were instructed to refrain from caffeinated beverages and food. Compliance was verified by assessing caffeine metabolites from fingertip sweat collected prior to habitual bedtime (see supplementary materials). The length of the treatment of 10 days was based on the maximum duration of withdrawal symptoms [20], occurring during placebo treatment in habitual consumers. Timing and dose were based on an earlier study investigating tolerance to caffeine and its withdrawal [10]. 
The caffeine and placebo conditions included one type of pill exclusively (caffeine or placebo, respectively). The withdrawal condition comprised a switch from caffeine to placebo pills in the late morning of day nine (+255 min after wake-up). In scheduling the caffeine to placebo switch to the late morning, a coincidence of the peak of withdrawal symptoms (after around $35 \mathrm{~h}$ after last caffeine intake) with a window of high circadian wake-promotion was aimed for. Dim light melatonin onset (DLMOnset) was used as marker of circadian timing.

Each condition started with an ambulatory part of nine days during which participants ingested capsules according to the regimen described above. In addition, participants kept a fixed sleepwake rhythm (within \pm 30 min of self-selected bedtime, time in bed $8 \mathrm{~h}$, no naps) verified by wrist actimetry (Actiwatch, Cambridge Neurotechnology, Cambridge, United Kingdom). The average deviation from the targeted bedtime was $\pm 21 \mathrm{~min}$ in the evening and $\pm 26 \mathrm{~min}$ in the morning with an average time in bed of $8 \mathrm{~h}$ and $3 \mathrm{~min}$. The sleep-wake schedule was consistent across the conditions except for three volunteers (twice: +30 min in caffeine compared to placebo and withdrawal conditions; once: $-30 \mathrm{~min}$ in placebo compared to caffeine and withdrawal conditions). Compliance to drug abstinence was checked prior to each laboratory part by a urinary toxicology screen (AccuBioTech Co. Ltd, Beijing, China).

In the evening on day nine of treatment, $5.5 \mathrm{~h}$ before individual habitual bedtime, a 43-h laboratory part started, schematically illustrated in Figure 1(b). Volunteers were accommodated in single apartments, isolated from external time cues and communication was restricted to team members. Additionally, light conditions ( $<8$ lux), posture and meal intake was controlled.

[insert Figure 1]

\section{Salivary caffeine}

Saliva samples to quantify caffeine levels were collected in intervals of approximately $2 \mathrm{~h}$ during scheduled wakefulness during the laboratory stay. Subsequently, caffeine levels were analysed with liquid chromatography coupled to tandem mass spectrometry. One dataset was not included due to its non-availability. 


\section{Neurobehavioural assessments}

Subjective sleepiness was assessed regularly with the Karolinska Sleepiness Scale (KSS) [30] every 30 to 60 min during scheduled wakefulness. For analyses, values were binned to 4-h intervals. Vigilance performance was measured by a visual 10-minute psychomotor vigilance task (PVT) [31], every $4 \mathrm{~h}$ during scheduled wakefulness. Volunteers were instructed to focus on a white cross displayed on a black screen and to respond as fast as possible by a key press as soon as a millisecond counter appeared. The inter-stimulus interval was randomised between 2 and $10 \mathrm{~s}$. Here, we focus on the number of lapses (reaction time $>500 \mathrm{~ms}$ ), the most sensitive measure for the interaction of caffeine with both sleep pressure and circadian phase [19]. As one of the tests was conducted in a magnetic resonance scanner with a compatible button box, lapses were z-transformed before analyses according to this change in environment.

\section{Salivary melatonin and cortisol}

Saliva samples were collected regularly in intervals of 30 to $60 \mathrm{~min}$. For handling, see supplementary materials. Melatonin and cortisol levels were detected using a direct doubleantibody radio immunoassay [32] and an enzyme-linked immunosorbent assay (ALPCO, Salem, $\mathrm{NH}$, USA), respectively. For analyses, data were collapsed into bins of $1.5 \mathrm{~h}$.

Four datasets were excluded from melatonin analyses due to insufficient data quality (placebo condition: one; caffeine condition: two; withdrawal condition: one). For analyses of melatonin, data were resampled every minute by applying linear interpolation. Subsequently, a bimodal skewed baseline cosine function (BSBCF) curve [33] was fitted to the data based on [34] with the modified cost function proposed in [35]. Goodness of fit $\left(R^{2}\right)$ was acceptable for all datasets (indicator > 0.6) except for two volunteers (placebo condition: one; caffeine condition: one). DLMOnset and dim light melatonin offset (DLMOffset) were determined for the fitted BSBCF curve applying a threshold of 0.1 of its amplitude which was defined by the difference between peak to baseline levels [33]. In order to estimate condition-specific changes in the melatonin profile, the amplitude and the area under the curve (AUC) were calculated including samples following wake-up at day 10 of treatment. 


\section{Polysomnography during nap sleep}

To test caffeine-induced differences in circadian wake-promotion, EEG was recorded during a one hour nap episode in the evening, starting $14.5 \mathrm{~h}$ after wake-up. It has repeatedly been shown that the ability to sleep is lowest in the evening [36,37], mirroring maximal wakepromoting strength at the end of the day. Recorded EEG data were visually scored according to [38], blind to the condition, yet slow-wave sleep (SWS) was further classified into stages 3 and 4 [39]. For details on recording procedure and scoring, see supplementary materials.

Total sleep time (TST) was calculated as sum of sleep stages 1, 2, 3, 4 and rapid eye movement (REM) sleep. Sleep efficiency (SE) was calculated as TST divided by time in bed. SWS comprises the sum of sleep stage 3 and 4 . Sleep latency 1 and 2 were defined as latency to the first occurrence of sleep stage 1 and 2, respectively. Non-REM (NREM) sleep was calculated as sum of stages 2, 3 and 4. Duration of REM sleep was not analysed as most participants $(\mathrm{N}=16,93 \%)$ did not reach this sleep state. To test condition-specific differences in the time course of nap sleep, time spent asleep (stages 1, 2, 3, 4 and REM sleep) and SWS were collapsed into 5-min time bins.

Spectral analysis of NREM sleep was conducted using a fast Fourier transformation (FFT) on 4s time windows (hamming, $0 \%$ overlapped) resulting in $0.25 \mathrm{~Hz}$ bins. Frequency bins from $0.5-$ $32 \mathrm{~Hz}$ of NREM sleep, recorded from frontal derivations (F3, F4), were analysed. Data were logtransformed and collapsed into $1 \mathrm{~Hz}$ bins. Note that condition-specific analyses are based on a reduced number of datasets because 10 participants did not initiate NREM sleep in at least one of the three conditions (four participants in placebo, six participants in caffeine, none in the withdrawal condition).

\section{Statistical analyses}

Data analyses were conducted with the statistical analyses software (SAS Institute, Cary, NC, USA) version 9.4 using mixed model analysis of variance (PROC MIXED) with subject as a random factor and the two repeated factors condition (three levels: placebo, caffeine and withdrawal) and time (levels differ per variable). To account for correlations between adjacent points within time, we used $\mathrm{AR}(1)$ as covariance structure (i.e. autoregressive (1)). In analyses 
without the factor time, we assumed CS (i.e. compound symmetry) to model the covariance structure most properly. Degrees of freedom were adjusted based on Kenward-Roger [40]. Plevels of post-hoc comparisons, derived from the LSMEANS statement, were corrected for multiple comparisons with the Tukey-Kramer method. Data of one participant in the caffeine condition have been excluded from all analyses due to incompliance to the treatment.

\section{Results}

\section{Caffeine levels}

As expected, caffeine levels were higher in the caffeine condition compared to both the withdrawal and placebo conditions (main effect of condition: $F_{2,121}=185.16 ; p<0.0001$; posthoc tests: $p<0.0001$ ) while levels during withdrawal were increased compared to the placebo condition (post-hoc tests: $p=0.035$; mean \pm SD: placebo: $18.52 \pm 84.80 \mathrm{ng} / \mathrm{ml}$; caffeine: $3024.18 \pm 2163.68 \mathrm{ng} / \mathrm{ml}$; withdrawal: $296.81 \pm 683.42 \mathrm{ng} / \mathrm{ml}$ ). As illustrated in Figure 2, this general pattern was modulated by time (interaction condition $x$ time: $F_{22,237}=2.76 ; p<0.0001$ ), mirroring both a decrease of caffeine levels during withdrawal condition and an increase in the caffeine condition after administration of treatment.

[insert Figure 2]

\section{Subjective sleepiness and vigilance performance}

The time course of subjective sleepiness values for each of the three conditions is illustrated in Figure 3(a) and the number of lapses on the PVT in Figure 3(b).

The results of the mixed model analysis of variance indicated higher subjective sleepiness in the withdrawal condition compared to the placebo and caffeine conditions (main effect of condition: $F_{2,58.2}=9.71 ; p<0.001$, post-hoc tests: $p<0.01$; mean \pm SD: placebo: $4.72 \pm 1.78$; caffeine: $4.66 \pm 1.91$; withdrawal: $5.27 \pm 1.81)$. A significant main effect of time $\left(F_{7,127}=54.62 ; p\right.$ $<0.0001)$ confirmed a diurnal profile with higher sleepiness during the biological night compared to daytime. 
The analyses of the number of lapses on the PVT yielded a significant main effect of condition $\left(F_{2,50.5}=6.66 ; p=0.0027\right.$; post-hoc tests: $\left.p<0.01\right)$ revealing more lapses during the withdrawal condition compared to the placebo and caffeine conditions (mean \pm SD: placebo: $-0.18 \pm 0.77$; caffeine: $-0.09 \pm 1.04$; withdrawal: $0.27 \pm 1.11)$. A significant main effect of time $\left(F_{6,98.2}=7.55 ; p\right.$ $<0.0001$ ) indicated a typical profile of more lapses during the night compared to daytime.

[insert Figure 3]

\section{Melatonin and cortisol}

In the analyses of melatonin levels, only the main effect of the factor time $\left(F_{17,290}=33.44 ; p<\right.$ 0.0001) was significant, confirming a diurnal profile of higher melatonin levels during the night compared to morning (Figure 4(a)). Neither DLMOnset $\left(F_{2,33.4}=1.16 ; p=0.325\right)$ nor DLMOffset $\left(F_{2,35.3}=1.32 ; p=0.280\right)$ significantly differed between conditions. Similarly, the effect of condition on amplitude $\left(F_{2,33.8}=0.57 ; p=0.573\right)$ and $A \cup C\left(F_{2,33.8}=1.77 ; p=0.185\right)$ on day 10 of treatment did not reach significance. For means and standard errors of the melatonin outcomes, see Table S4.

Analyses of cortisol levels did not show significant differences between conditions $\left(F_{2,129}=0.43\right.$; $p=0.653)$. However, a significant main effect of the factor time $\left(F_{17,303}=31.66 ; p<0.0001\right)$ demonstrated a normal diurnal pattern with higher cortisol levels in the morning and lower levels during the night. The time course of salivary cortisol levels is illustrated in Figure 4(b).

[insert Figure 4]

\section{Evening nap sleep}

A summary of sleep variables per condition and results of the statistical analyses are presented in Table 1. TST and SWS were longer, and SE was higher during withdrawal compared to placebo and caffeine conditions (post-hoc tests: $p<0.05$ ). Furthermore, sleep latency to sleep stage 1 and stage 2 were shorter during withdrawal compared to placebo and caffeine conditions (post-hoc tests: $p<0.05$ ). Generally, initiation of NREM sleep was less frequent in 
the caffeine and placebo conditions compared to withdrawal (no NREM sleep in placebo: $\mathrm{N}=4$, caffeine: $\mathrm{N}=6$, and withdrawal condition: $\mathrm{N}=0$, Cochrans Q-test: $p<0.05$ ).

Table 1. Sleep parameters derived from visual scoring assessed during evening nap sleep.

\begin{tabular}{|lrrrl|}
\hline Sleep Parameter & \multicolumn{1}{c}{ Placebo } & \multicolumn{1}{c|}{ Caffeine } & Withdrawal & Factor Condition \\
\hline TST $(\mathrm{min})$ & $31.63 \pm 3.90$ & $24.26 \pm 4.55$ & $43.88 \pm 2.83^{\mathrm{a}}$ & $F(2,37.3)=9.64, p<0.001$ \\
SE $(\%)$ & $52.71 \pm 6.50$ & $40.44 \pm 7.58$ & $73.12 \pm 4.72^{\mathrm{a}}$ & $F(2,37.3)=9.64, p<0.001$ \\
Stage 1 $(\mathrm{min})$ & $4.95 \pm 0.73$ & $4.66 \pm 0.83$ & $5.80 \pm 0.85$ & $F(2,37.6)=0.67, p=0.519$ \\
Stage 2 $(\mathrm{min})$ & $12.10 \pm 1.97$ & $9.82 \pm 2.22$ & $15.30 \pm 1.57^{\mathrm{b}}$ & $F(2,37.2)=3.85, p=0.030$ \\
Stage 3 $(\mathrm{min})$ & $6.53 \pm 1.48$ & $5.74 \pm 1.73$ & $10.20 \pm 1.96^{\mathrm{b}}$ & $F(2,37.4)=4.09, p=0.025$ \\
Stage 4 $(\mathrm{min})$ & $6.80 \pm 2.16$ & $3.74 \pm 2.01$ & $11.48 \pm 2.69^{\mathrm{b}}$ & $F(2,37.2)=6.06, p=0.005$ \\
SWS $(\mathrm{min})$ & $13.33 \pm 2.82$ & $9.47 \pm 2.70$ & $21.68 \pm 3.00^{\mathrm{a}}$ & $F(2,37.3)=8.22, p=0.001$ \\
NREM $(\mathrm{min})$ & $25.43 \pm 4.01$ & $19.29 \pm 4.27$ & $36.98 \pm 3.34^{\mathrm{a}}$ & $F(2,37.1)=8.87, p<0.001$ \\
SL1 $(\mathrm{min})$ & $25.70 \pm 3.94$ & $28.51 \pm 4.57$ & $12.09 \pm 2.11^{\mathrm{a}}$ & $F(2,37.4)=7.59, p=0.002$ \\
SL2 $(\mathrm{min})$ & $31.16 \pm 4.11$ & $37.94 \pm 4.51$ & $18.39 \pm 2.87^{\mathrm{a}}$ & $F(2,37.3)=9.80, p<0.001$ \\
\hline
\end{tabular}

Values are for means \pm standard errors. TST: total sleep time; SE: sleep efficiency; SWS: slow-

wave sleep (stage $3+4$ ); NREM: non-rapid eye movement sleep; SL1: sleep latency to sleep stage 1; SL2: sleep latency to sleep stage 2.

a $p<0.05$ compared to placebo and caffeine conditions.

${ }^{\mathrm{b}} p<0.05$ compared to caffeine condition.

In a next step we were interested whether time spent asleep and SWS accumulate differently depending on the treatment. As depicted in Figure 5, particularly in the beginning of the nap, time spent asleep and SWS accumulated faster during the withdrawal condition compared to caffeine and placebo conditions (interaction condition $\mathrm{x}$ time for time spent asleep: $F_{22,354}=$ $5.40 ; p<0.0001 ;$ and SWS: $\left.F_{22,354}=3.82 ; p<0.0001\right)$.

[insert Figure 5]

In a final step, differences in spectral power density between conditions were analysed. There were no significant differences in spectral power density between caffeine and placebo. However, spectral power density was reduced in the sigma range during withdrawal compared to placebo condition ( $15 \mathrm{~Hz}: F_{2,27.4}=3.48 ; p=0.045 ; 16 \mathrm{~Hz}: F_{2,27.6}=3.15 ; p=0.059$ ). 


\section{Discussion}

The aim of the present study was to examine the effects of daily caffeine intake and its cessation on circadian timing, wake-promotion and the course of neurobehavioural indices in habitual consumers under entrained conditions. Making use of a carefully controlled withinsubject design, we focused on the effects of repeated daily consumption in the morning and afternoon, as this is the typical pattern in the society nowadays. Under these conditions, neither caffeine consumption nor its cessation affected the diurnal profile of melatonin or cortisol secretion. However, for more than $20 \mathrm{~h}$, cessation of intake induced a state of withdrawal, characterised by higher subjective sleepiness, impaired vigilance performance and a higher drive to sleep even at a phase of high circadian wake-promotion. It is concluded that daily daytime intake of caffeine throughout the morning and afternoon does not strongly affect human circadian rhythms under entrained conditions. Still, it induces adaptations, potentially at the level of the adenosine receptors, which come to light as a state of reduced arousal and alertness as soon as caffeine intake is ceased.

In animal studies, long-term treatment with caffeine leads to a different timing of circadian restactivity rhythms, specifically to a lengthening of circadian period under constant lighting conditions $[41,42]$. Similar observations in unmasked human rest-activity cycles are missing so far. However, under conditions of forced desynchronisation between the timing of circadian rhythms and sleep-wake cycles, circadian plasma melatonin rhythms were not altered in response to hourly administration of caffeine over four weeks [19]. The results of the present study add that - under entrained conditions - the timing of both melatonin and cortisol does not necessarily change by daily caffeine consumption in the morning, midday and afternoon, a temporal pattern which is commonly observed in habitual consumers [16]. Importantly, based on the absence of a clear-cut shift in circadian timing in the withdrawal condition, it seems unlikely that the participants might have developed tolerance to the phase-shifting effects of the drug. Please note, however, that apart from statistics on the group's average, visual inspection revealed a delay in DLMOffset during caffeine in more than half of the volunteers $(N=13$, see supplementary materials). Thus, interindividual differences in response to the stimulant [43] as well as the small sample size might have hampered statistical condition-specific differences at $p$ 
$<0.05$. Interestingly, one [18] of three $[18,41,44]$ animal studies on the effects of repeated caffeine intake suggests a slight delay in activity onset of mice under normal light-dark cycles. However, in naïve animals no phase-shift in locomotor activity pattern has been found if caffeine was administered at activity onset [45]. In humans, a one-time treatment before regular wake-up time could have the potential to prevent dim-light induced phase delays (Burke and Wright, personal communication [46]). Together, the effects of caffeine intake on circadian timing in the morning hours might thus differ according to treatment continuity (i.e. acute vs chronic). Moreover, the available evidence indicates that the effects of repeated daytime caffeine intake on human circadian timing when consumed in the morning, midday and afternoon under entrained conditions seem to be small.

Most likely, however, the effects of caffeine on circadian rhythms depend on the time of intake. While there is evidence that morning caffeine intake prevents dim-light induced phase delays (Burke and Wright, personal communication [46]), caffeine administration in the evening delays circadian phase [13]. As a consequence caffeine taken throughout the day as in the present study may have cancelled out any potential phase shifting effects. So far, a delay [13] or reduction in melatonin [14] in humans, either abstinent [13] or potentially under withdrawal [14], was specifically induced after a caffeine treatment in the evening or at night. In contrast, repeated caffeine intake in the morning did not successfully entrain three blind patients [47]. Furthermore, a recent animal study under constant conditions suggests that caffeine treatment does only potentiate light-induced phase shifts when given at the end of the active phase or during rest, but not at the start of the active phase [45]. Together with the present results, the evidence suggests that the circadian system seems to be particularly sensitive to caffeine when given at the end of the biological day. Future studies might disentangle circadian and sleephomeostatic contributions to this effect. Independent of time-of-day, we observed clear-cut effects induced by caffeine withdrawal. In line with earlier studies [20], the acute challenge of cessation from caffeine was associated with signs of increased sleep pressure, such as increased subjective sleepiness and worse vigilance performance during day and nighttime as well as a faster initiation of NREM sleep even at a time of high circadian wake-promotion. Thus, the preceding repeated presence of caffeine might have induced compensatory adaptations at 
the neuronal level [23], which modulate the stimulatory effects of caffeine and underlie the effects of withdrawal as soon as consumption is stopped. Several changes have been associated with long-term caffeine intake, e.g. upregulation of adenosine receptors [48-51], increased plasma adenosine concentrations [52] or modulations in the function of adenosine heteromers [53]. These neuronal changes in the adenosinergic system might alter the homeostatic sleep need. In the present study, an increased sleep pressure experienced during caffeine withdrawal might have overruled the circadian drive for wake-promotion in the evening, a phenomenon which has already been shown after sleep restriction in humans [54]. In contrast to the clear-cut symptoms of caffeine withdrawal in behaviour, we do not have any indication for a significant difference in either of the measured variables during daily caffeine consumption compared to placebo. Importantly our study was designed to focus on the effects of caffeine after a certain period of repeated intake under normal sleep-wake conditions. In earlier studies that showed a caffeine-induced sleep disruption during circadian wake-promotion after continuous daily intake, measurements were taken under relatively high levels of sleep pressure (i.e. after $25 \mathrm{~h}$ [55] or $28 \mathrm{~h}$ [19] of wakefulness). Interestingly, reviews indeed suggest that the stimulating properties of caffeine are most prominently under high sleep pressure such as after sleep deprivation or sleep restriction $[3,12]$. Therefore, we may not exclude that caffeine intake would have induced sleep disruption and alertness under a longer duration of wakefulness as was applied in the present study. However, studies controlling for withdrawal reversal, similarly applied in our study, failed to show a caffeine-induced improvement in performance in sleep-restricted subjects [56,57], indicating that improvements by caffeine cannot solely be explained by sleep-wake-history but probably also depend on preceding caffeine intake. Applying repeated caffeine administrations and an ambulatory period of nine days prior to each assessment phase, potential effects in the caffeine condition deriving from withdrawal reversal and carry-over effects can likely be excluded.

Moreover, one might argue that the lack of improvement in subjective alertness and performance during caffeine intake compared to placebo condition is due to a floor effect. In other words, the low sleepiness and high performance level occurring during the placebo condition did not leave much room for additional improvement by caffeine. However, our 
measurements took place also during the biological night, in which we observed the typical nighttime decrease in alertness and performance. As we did not observe a significant caffeineinduced improvement under these conditions, our results suggest that the effects of daytime caffeine intake on alertness and performance are either short-lasting, small or not present under conditions of habitual daily caffeine intake.

Finally, the development of tolerance could have been induced by regular daily caffeine consumption. There are convincing indicators for tolerance to occur after 3-5 days of habitual caffeine intake [58] during both wakefulness and sleep with the potential of complete [59] or partial tolerance $[17,60]$. Moreover, the current results in subjective sleepiness and vigilance performance during caffeine cessation provide evidence for an adaptation to the daily exposure of caffeine, however, circadian timing and amplitude remain mainly unaffected. Within this context, it is important to note that the present study design does not include a condition assessing the effects of acute caffeine intake after long-term abstinence. Thus, we cannot provide a strict measure of tolerance by comparing acute effects of caffeine with the effects after daily treatment in the same individuals. This is of particular interest, as the habitual consumption level in the present sample might be an indicator for a reduced sensitivity to react to caffeine [61]. Nevertheless, doses of $400 \mathrm{mg}$ have been shown to induce certain performance benefits in habitual consumers [62] and it is still debatable whether there is a dosedependent saturation of caffeine-induced performance benefits at $200 \mathrm{mg}$ as suggested by [63] (but see $[63,64])$.

We are aware that this study may have several limitations which have to be taken into careful consideration. First, no washout phase was scheduled between the conditions. However, we implemented an ambulatory part with a fixed sleep-wake schedule and a constant treatment during nine days preceding data collection in the lab. Thus, circadian and sleep-wake systems might have returned to a normal state and recovered from previous conditions. Second, the exclusion of female volunteers clearly limits the generalisability of the present results. We studied male participants only in order to avoid potential confounding by the menstrual cycle on caffeine elimination [65] and sleep-wake regulation and thus on our main outcome variables e.g. melatonin, cortisol and sleep [26]. Moreover, we aimed at reducing variance in the data due to 
the potential use of oral contraceptives which have been shown to change caffeine clearance $[27,28]$ and its effect depending on the duration of oral contraceptive use [66]. Third, we studied volunteers with an age range of 18-35 years. As evidence suggests an age-related modulation of caffeine-effects on cognition $[67,68]$ and sleep $[69,70]$ our results are not necessarily transferable to other age groups such as teenagers or adults older than 40 years. Fourth, in the present study regular caffeine consumers were studied of which some reported habitual caffeine consumption in the evening (see supplementary materials). However, evening caffeine intake is not common [16] presumably due to potential sleep-disruption [6] and thus might be an indicator of a certain insensitivity to the effects of caffeine. While the observed clear-cut withdrawal-induced effects make it unlikely that our sample was entirely unresponsive to the stimulant, the impact of caffeine might be stronger as compared to our sample in more sensitive individuals. Last, no genetic information including variations in the adenosine $A_{2 A}$ receptor gene (ADORA2A) were collected, which have been previously associated with habitual caffeine intake and insensitivity to the effects of the stimulant [61]. However, based on the clear-cut changes in performance and sleepiness when caffeine was ceased, it is unlikely that volunteers were insensitive to the effects of caffeine but rather developed tolerance due to the repeated intake of the stimulant.

Taken together, this is the first study investigating the impact of habitual caffeine consumption on human circadian rhythms under entrained conditions. The study was designed to focus on the effects of a typical pattern of caffeine consumption with daily intake in the morning, midday and afternoon. We provide first evidence that this type of exposure to the stimulant does not considerably shift circadian markers such as melatonin and cortisol nor does it lead to an increased wake-promotion in the evening. However, the acute challenge of cessation from caffeine was associated with signs of increased sleep pressure. Together, our data point to an adaptation of waking-performance to habitual exposure to the stimulant while circadian markers remain fairly stable. These mechanisms of both adaptation and robustness might enable normal sleep-wake states during constant supply of a stimulating agent in the central nervous system. 


\section{Funding}

The study was carried out in the framework of a project granted by the Swiss National Science Foundation (320030_163058). Additionally, the present work was supported by the Nikolaus und Bertha Burckhardt-Bürgin-Stiftung and the Janggen-Pöhn-Stiftung.

\section{Acknowledgements}

We thank our interns Andrea Schumacher, Laura Tincknell, Sven Leach and all the study helpers for their great help in data collection, Claudia Renz for the analyses of melatonin and cortisol, Dr. Ruta Lasauskaite for her help in study organisation, Dr. med. Martin Meyer and Dr. med. Helen Slawik for the physical examinations, and all our volunteers for study participation.

\section{Conflict of interest}

The authors declare that there is no conflict of interest. 


\section{References}

1 Fredholm BB, Battig K, Holmen J, Nehlig A, Zvartau EE. Actions of caffeine in the brain with special reference to factors that contribute to its widespread use. Pharmacol Rev. 1999;51(1):83-133.

2 Heckman MA, Weil J, Gonzalez de Mejia E. Caffeine (1, 3, 7-trimethylxanthine) in foods: a comprehensive review on consumption, functionality, safety, and regulatory matters. J Food Sci. 2010;75(3):R77-87.

3 Roehrs T, Roth T. Caffeine: sleep and daytime sleepiness. Sleep Med Rev. 2008;12(2):153-62.

4 Camandola S, Plick N, Mattson MP. Impact of Coffee and Cacao Purine Metabolites on Neuroplasticity and Neurodegenerative Disease. Neurochem Res. 2019;44(1):214-27.

5 Borbély AA. A two process model of sleep regulation. Hum Neurobiol. 1982;1(3):195204.

6 Landolt HP. Sleep homeostasis: a role for adenosine in humans? Biochem Pharmacol. 2008;75(11):2070-9.

7 Porkka-Heiskanen T. Sleep homeostasis. Curr Opin Neurobiol. 2013;23(5):799-805.

8 Elmenhorst D, Meyer PT, Matusch A, Winz OH, Bauer A. Caffeine occupancy of human cerebral A1 adenosine receptors: in vivo quantification with 18F-CPFPX and PET. J Nucl Med. 2012;53(11):1723-9.

9 Naganawa M, Mishina M, Sakata M, Oda K, Hiura M, Ishii K, et al. Test-retest variability of adenosine A2A binding in the human brain with (11)C-TMSX and PET. EJNMMI Res. 2014;4(1):76

10 James JE. Acute and chronic effects of caffeine on performance, mood, headache, and sleep. Neuropsychobiology. 1998;38(1):32-41.

11 Einöther SJL, Giesbrecht T. Caffeine as an attention enhancer: reviewing existing assumptions. Psychopharmacology. 2013;225(2):251-74.

12 Snel J, Lorist MM. Effects of caffeine on sleep and cognition. Prog Brain Res. 2011;190:105-17. 
13 Burke TM, Markwald RR, McHill AW, Chinoy ED, Snider JA, Bessman SC, et al. Effects of caffeine on the human circadian clock in vivo and in vitro. Sci Transl Med. $2015 ; 7(305)$.

14 Wright KP, Jr., Badia P, Myers BL, Plenzler SC, Hakel M. Caffeine and light effects on nighttime melatonin and temperature levels in sleep-deprived humans. Brain Res. 1997;747(1):78-84.

15 Wright KP, Jr., Myers BL, Plenzler SC, Drake CL, Badia P. Acute effects of bright light and caffeine on nighttime melatonin and temperature levels in women taking and not taking oral contraceptives. Brain Res. 2000;873(2):310-7.

16 Martyn D, Lau A, Richardson P, Roberts A. Temporal patterns of caffeine intake in the United States. Food Chem Toxicol. 2018;111:71-83.

17 Bonnet MH, Arand DL. Caffeine use as a model of acute and chronic insomnia. Sleep. 1992;15(6):526-36.

18 Panagiotou M, Meijer M, Meijer JH, Deboer T. Effects of chronic caffeine consumption on sleep and the sleep electroencephalogram in mice. J Psychopharmacol. 2018:269881118806300

19 Wyatt JK, Cajochen C, Ritz-De Cecco A, Czeisler CA, Dijk DJ. Low-dose repeated caffeine administration for circadian-phase-dependent performance degradation during extended wakefulness. Sleep. 2004;27(3):374-81.

20 Juliano LM, Griffiths RR. A critical review of caffeine withdrawal: empirical validation of symptoms and signs, incidence, severity, and associated features. Psychopharmacology. 2004;176(1):1-29.

21 Rogers PJ, Heatherley SV, Hayward RC, Seers HE, Hill J, Kane M. Effects of caffeine and caffeine withdrawal on mood and cognitive performance degraded by sleep restriction. Psychopharmacology (Berl). 2005;179(4):742-52.

22 Sigmon SC, Herning RI, Better W, Cadet JL, Griffiths RR. Caffeine withdrawal, acute effects, tolerance, and absence of net beneficial effects of chronic administration: cerebral blood flow velocity, quantitative EEG, and subjective effects. Psychopharmacology (Berl). 2009;204(4):573-85. 
23 Ferre $\mathrm{S}$. An update on the mechanisms of the psychostimulant effects of caffeine. $\mathrm{J}$ Neurochem. 2008;105(4):1067-79.

24 Horne JA, Ostberg O. A self-assessment questionnaire to determine morningnesseveningness in human circadian rhythms. Int J Chronobiol. 1976;4(2):97-110.

25 Buysse DJ, Reynolds CF, 3rd, Monk TH, Berman SR, Kupfer DJ. The Pittsburgh Sleep Quality Index: a new instrument for psychiatric practice and research. Psychiatry Res. 1989;28(2):193-213.

26 Shechter A, Boivin DB. Sleep, Hormones, and Circadian Rhythms throughout the Menstrual Cycle in Healthy Women and Women with Premenstrual Dysphoric Disorder. Int J Endocrinol. 2010;2010:259345.

27 Balogh A, Klinger G, Henschel L, Borner A, Vollanth R, Kuhnz W. Influence of ethinylestradiol-containing combination oral contraceptives with gestodene or levonorgestrel on caffeine elimination. Eur J Clin Pharmacol. 1995;48(2):161-6.

28 Abernethy DR, Todd EL. Impairment of caffeine clearance by chronic use of low-dose oestrogen-containing oral contraceptives. Eur J Clin Pharmacol. 1985;28(4):425-8.

29 Bühler E, Lachenmeier DW, Schlegel K, Winkler G. Development of a tool to assess the caffeine intake among teenagers and young adults. Ernahrungs Umschau 2013;61(4):58-63.

30 Akerstedt T, Gillberg M. Subjective and objective sleepiness in the active individual. Int J Neurosci. 1990;52(1-2):29-37.

31 Dinges DF, Powell JW. Microcomputer Analyses of Performance on a Portable, Simple Visual Rt Task during Sustained Operations. Behav Res Meth Instr. 1985;17(6):652-55. Weber JM, Schwander JC, Unger I, Meier D. A direct ultrasensitive RIA for the determination of melatonin in human saliva: comparison with serum levels. J Sleep Res. 1997;26:757.

33 Van Someren EJ, Nagtegaal E. Improving melatonin circadian phase estimates. Sleep Med. 2007;8(6):590-601. 
34 Kolodyazhniy V, Späti J, Frey S, Gotz T, Wirz-Justice A, Kräuchi K, et al. An improved method for estimating human circadian phase derived from multichannel ambulatory monitoring and artificial neural networks. Chronobiol Int. 2012;29(8):1078-97.

35 Gabel V, Reichert CF, Maire M, Schmidt C, Schlangen LJM, Kolodyazhniy V, et al. Differential impact in young and older individuals of blue-enriched white light on circadian physiology and alertness during sustained wakefulness. Sci Rep. 2017;7(1):7620.

36 Dijk DJ, Czeisler CA. Paradoxical timing of the circadian rhythm of sleep propensity serves to consolidate sleep and wakefulness in humans. Neurosci Lett. 1994;166(1):638.

37 Strogatz SH, Kronauer RE, Czeisler CA. Circadian pacemaker interferes with sleep onset at specific times each day: role in insomnia. Am J Physiol. 1987;253(1 Pt 2):R172-8.

38 Berry RB, Brooks R, Gamaldo CE, Harding SM, Marcus CL, Vaughn BV, et al. The AASM manual for the scoring of sleep and associated events: rules, terminology and technical specifications, version 2.0. American Academy of Sleep Medicine: Darien, IL. 2012.

39 Rechtschaffen A, Kales A. A manual of standardized terminology, techniques and scoring system for sleep stages of human subjects. US Dept of Health, Education and Welfare, Public Health Service: Bethesda, MD. 1968.

40 Kenward MG, Roger JH. Small sample inference for fixed effects from restricted maximum likelihood. Biometrics. 1997;53(3):983-97.

41 Oike H, Kobori M, Suzuki T, Ishida N. Caffeine lengthens circadian rhythms in mice. Biochem Biophys Res Commun. 2011;410(3):654-8.

42 van Diepen HC, Lucassen EA, Yasenkov R, Groenen I, ljzerman AP, Meijer JH, et al. Caffeine increases light responsiveness of the mouse circadian pacemaker. Eur $\mathrm{J}$ Neurosci. 2014;40(10):3504-11. 
43 Fulton JL, Dinas PC, Carrillo AE, Edsall JR, Ryan EJ, Ryan EJ. Impact of Genetic Variability on Physiological Responses to Caffeine in Humans: A Systematic Review. Nutrients. 2018;10(10).

44 Narishige S, Kuwahara M, Shinozaki A, Okada S, Ikeda Y, Kamagata M, et al. Effects of caffeine on circadian phase, amplitude and period evaluated in cells in vitro and peripheral organs in vivo in PER2::LUCIFERASE mice. $\mathrm{Br} \mathrm{J}$ Pharmacol. 2014;171(24):5858-69.

45 Jha PK, Bouaouda H, Gourmelen S, Dumont S, Fuchs F, Goumon Y, et al. Sleep Deprivation and Caffeine Treatment Potentiate Photic Resetting of the Master Circadian Clock in a Diurnal Rodent. J Neurosci. 2017;37(16):4343-58.

46 Burke T, Markwald R, Chinoy E, Snider J, Bessman S, Jung C, et al. Morning caffeine and the human circadian clock. Poster Presentation at the Meeting of the Society for Research on Biological Rhythms. 2018. Unpublished results.

47 St Hilaire MA, Lockley SW. Caffeine does not entrain the circadian clock but improves daytime alertness in blind patients with non-24-hour rhythms. Sleep Med. $2015 ; 16(6): 800-4$.

48 Varani K, Portaluppi F, Merighi S, Ongini E, Belardinelli L, Borea PA. Caffeine alters A2A adenosine receptors and their function in human platelets. Circulation. 1999;99(19):2499-502 .

49 Johansson B, Georgiev V, Lindstrom K, Fredholm BB. A1 and A2A adenosine receptors and A1 mRNA in mouse brain: effect of long-term caffeine treatment. Brain Res. 1997;762(1-2):153-64.

50 Fredholm BB. Adenosine actions and adenosine receptors after 1 week treatment with caffeine. Acta Physiol Scand. 1982;115(2):283-6.

51 Shi D, Nikodijevic O, Jacobson KA, Daly JW. Chronic caffeine alters the density of adenosine, adrenergic, cholinergic, GABA, and serotonin receptors and calcium channels in mouse brain. Cell Mol Neurobiol. 1993;13(3):247-61.

52 Conlay LA, Conant JA, deBros F, Wurtman R. Caffeine alters plasma adenosine levels. Nature. 1997;389(6647):136. 
53 Ciruela F, Casado V, Rodrigues RJ, Lujan R, Burgueno J, Canals M, et al. Presynaptic control of striatal glutamatergic neurotransmission by adenosine A1-A2A receptor heteromers. J Neurosci. 2006;26(7):2080-7.

54 Sargent C, Darwent D, Ferguson SA, Kennaway DJ, Roach GD. Sleep restriction masks the influence of the circadian process on sleep propensity. Chronobiol Int. 2012;29(5):565-71.

55 Carrier J, Paquet J, Fernandez-Bolanos M, Girouard L, Roy J, Selmaoui B, et al. Effects of caffeine on daytime recovery sleep: A double challenge to the sleep-wake cycle in aging. Sleep Med. 2009;10(9):1016-24.

56 Keane MA, James JE. Effects of dietary caffeine on EEG, performance and mood when rested and sleep restricted. Hum Psychopharmacol. 2008;23(8):669-80.

57 James JE, Gregg ME, Kane M, Harte F. Dietary caffeine, performance and mood: enhancing and restorative effects after controlling for withdrawal reversal. Neuropsychobiology. 2005;52(1):1-10.

58 James JE. Caffeine and cognitive performance: persistent methodological challenges in caffeine research. Pharmacol Biochem Behav. 2014;124:117-22.

59 Evans SM, Griffiths RR. Caffeine Tolerance and Choice in Humans. Psychopharmacology. 1992;108(1-2):51-59.

60 Watson J, Deary I, Kerr D. Central and peripheral effects of sustained caffeine use: tolerance is incomplete. Br J Clin Pharmacol. 2002;54(4):400-6.

61 Retey JV, Adam M, Khatami R, Luhmann UF, Jung HH, Berger W, et al. A genetic variation in the adenosine A2A receptor gene (ADORA2A) contributes to individual sensitivity to caffeine effects on sleep. Clin Pharmacol Ther. 2007;81(5):692-8.

62 Brunye TT, Mahoney CR, Lieberman HR, Giles GE, Taylor HA. Acute caffeine consumption enhances the executive control of visual attention in habitual consumers. Brain Cogn. 2010;74(3):186-92.

63 Brunye TT, Mahoney CR, Lieberman HR, Taylor HA. Caffeine modulates attention network function. Brain Cogn. 2010;72(2):181-8. 
64 Childs E, de Wit H. Subjective, behavioral, and physiological effects of acute caffeine in light, nondependent caffeine users. Psychopharmacology. 2006;185(4):514-23.

65 Lane JD, Steege JF, Rupp SL, Kuhn CM. Menstrual cycle effects on caffeine elimination in the human female. Eur J Clin Pharmacol. 1992;43(5):543-6.

66 Rietveld EC, Broekman MM, Houben JJ, Eskes TK, van Rossum JM. Rapid onset of an increase in caffeine residence time in young women due to oral contraceptive steroids. Eur J Clin Pharmacol. 1984;26(3):371-3.

67 Jarvis MJ. Does Caffeine Intake Enhance Absolute Levels of Cognitive Performance. Psychopharmacology. 1993;110(1-2):45-52.

68 Hogervorst E, Riedel WJ, Schmitt JAJ, Jolles J. Caffeine improves memory performance during distraction in middle-aged, but not in young or old subjects. Hum Psychopharm Clin. 1998;13(4):277-84.

69 Drapeau C, Hamel-Hebert I, Robillard R, Selmaoui B, Filipini D, Carrier J. Challenging sleep in aging: the effects of $200 \mathrm{mg}$ of caffeine during the evening in young and middle-aged moderate caffeine consumers. J Sleep Res. 2006;15(2):133-41.

70 Robillard R, Bouchard M, Cartier A, Nicolau L, Carrier J. Sleep is more sensitive to high doses of caffeine in the middle years of life. J Psychopharmacol. 2015;29(6):688-97.

71 Curran-Everett D. Multiple comparisons: philosophies and illustrations. Am J Physiol Regul Integr Comp Physiol. 2000;279(1):R1-8. 


\section{Figure legends}

Figure 1. Schematic illustration of study protocol.

(a) Each volunteer participated in a placebo, a caffeine and a withdrawal condition, each comprising a 43-h laboratory stay, preceded by an ambulatory part. In each condition either caffeine or placebo capsules were administered three times daily. (b) The laboratory stay started in the evening of day nine with assessments of subjective sleepiness, vigilance performance, salivary melatonin, cortisol and caffeine levels, which were continued on the next day after an 8-h baseline night. In the evening of day 10, $14.5 \mathrm{~h}$ after wake-up, a 1 -h nap was scheduled during a time of high circadian wake-promotion $[36,37]$ followed by $5.75 \mathrm{~h}$ of scheduled wakefulness and an 8-h recovery night.

Figure 2. Time course of caffeine levels across the $43 \mathrm{~h}$ under controlled laboratory conditions in the placebo (black open circles), caffeine (blue circles) and withdrawal (red semi-filled circles) condition. Pill administrations (caffeine or placebo) are depicted with dashed lines and the bottom $\mathrm{x}$-axis indicates the mean time of day during which samples have been collected. Symbols mark significant $(p<0.05)$ post-hoc comparisons of the interaction effect condition $\mathrm{x}$ time, corrected according to [71] for multiple comparisons (black triangles: placebo compared to caffeine, open triangles: withdrawal compared to caffeine, black square: withdrawal compared to placebo).

Figure 3. Time course of subjective sleepiness (a) and attentional lapses assessed during PVT (b) in the placebo (black open circles), caffeine (blue circles) and withdrawal (red semi-filled circles) condition across 43-h (means \pm standard errors). Pill administrations (caffeine or placebo) are depicted with dashed lines and the bottom $\mathrm{x}$-axis indicates the mean time of day during which samples have been collected. Both subjective sleepiness and vigilance performance were impaired after the abrupt cessation of caffeine compared to placebo and daily caffeine intake. 
Figure 4. Time course of salivary melatonin (a) and cortisol (b) across the 43-h laboratory stay. The means \pm standard errors are depicted for placebo (black open circles), caffeine (blue circles) and withdrawal (red semi-filled circles) conditions and pill administrations (caffeine or placebo) are indicated with dashed lines. The melatonin profile depicts the fitted data and the bottom $x$-axis indicates the mean time of day during which samples have been collected. The typical course of both melatonin and cortisol across a day is clearly visible, however being independent of the treatment.

Figure 5. Accumulation curves of time spent asleep and SWS during evening nap sleep. Data were collapsed into bins of 5 min and accumulated across the one hour. Means and standard errors are represented for placebo (black open circles), caffeine (blue circles) and withdrawal (red semi-filled circles). Asterisks mark significant differences to the first bin within the same condition $\left(p_{\text {all }}<0.05\right)$. 
Figure 1

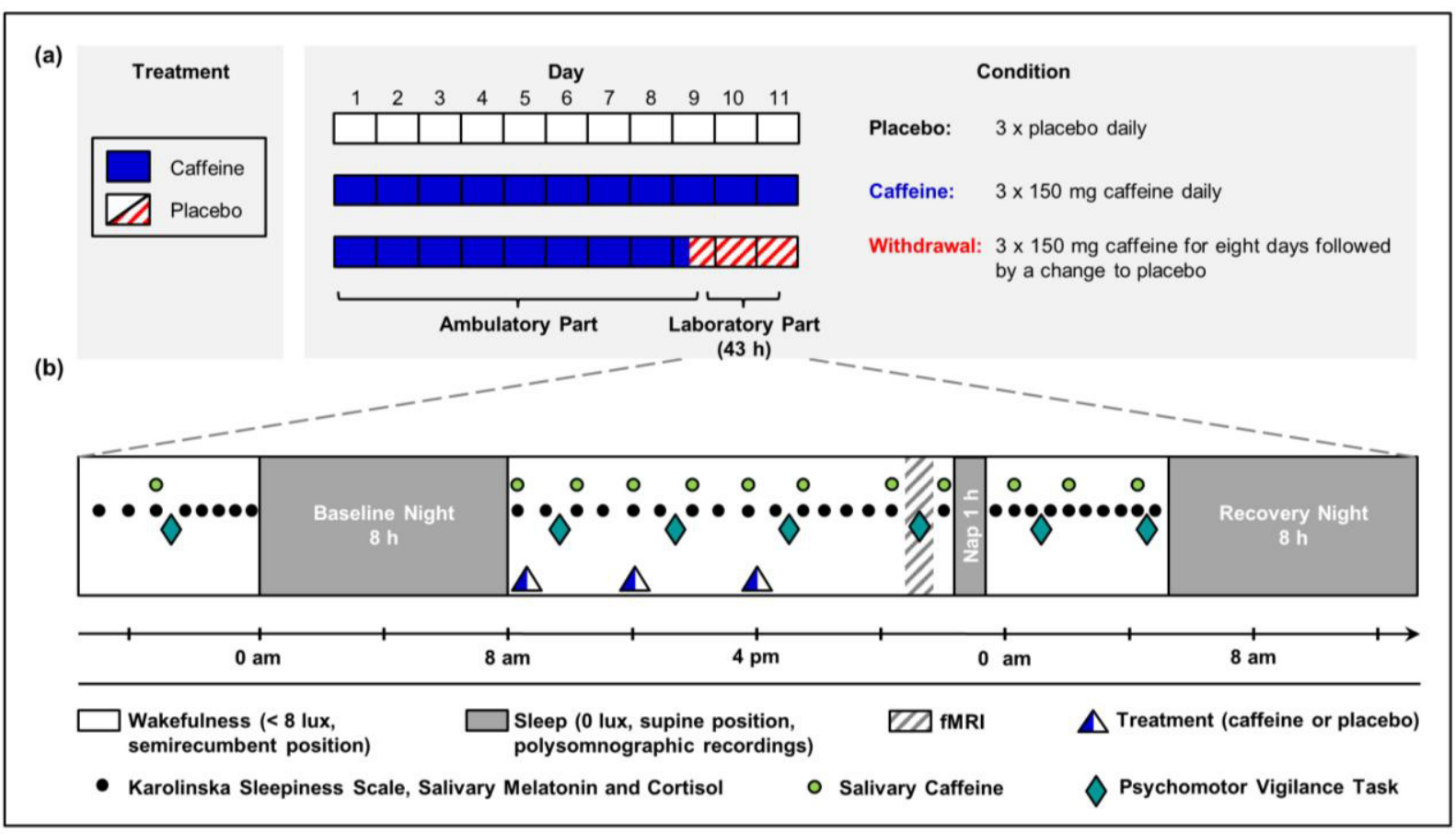


Figure 2

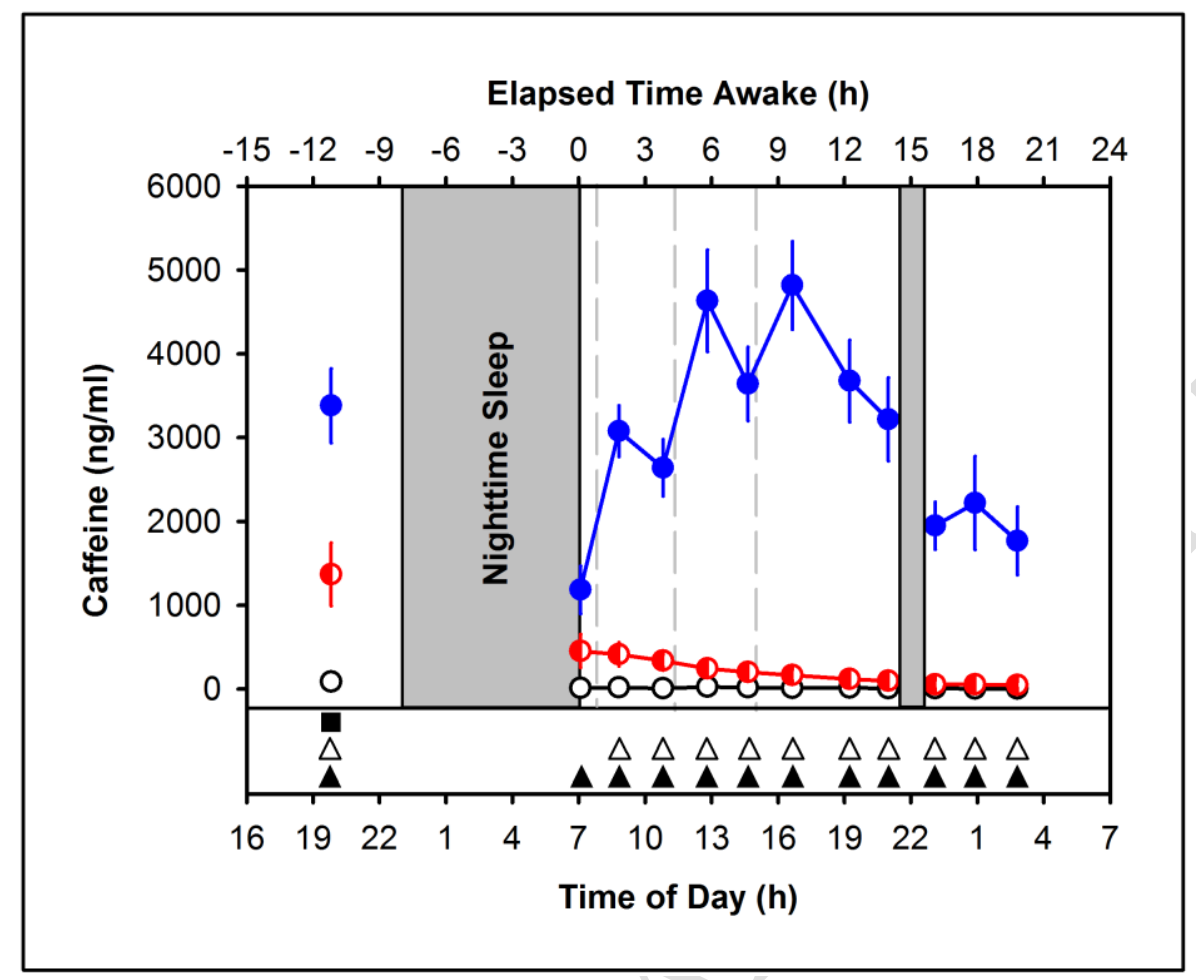


Figure 3

(a)

Elapsed Time Awake (h)

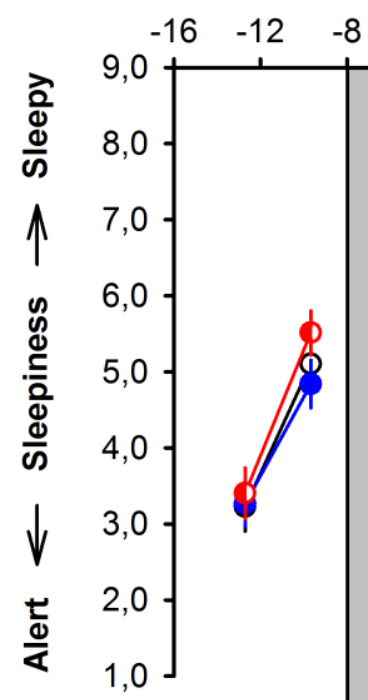

(b)

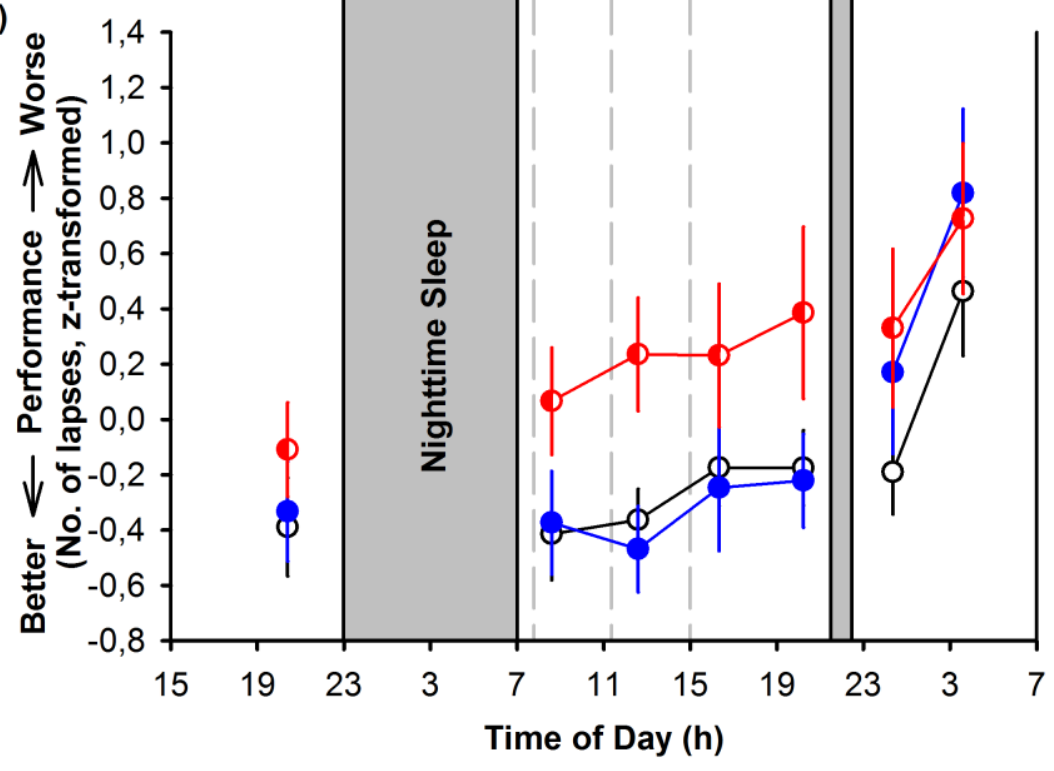


Figure 4

(a)

Elapsed Time Awake (h)
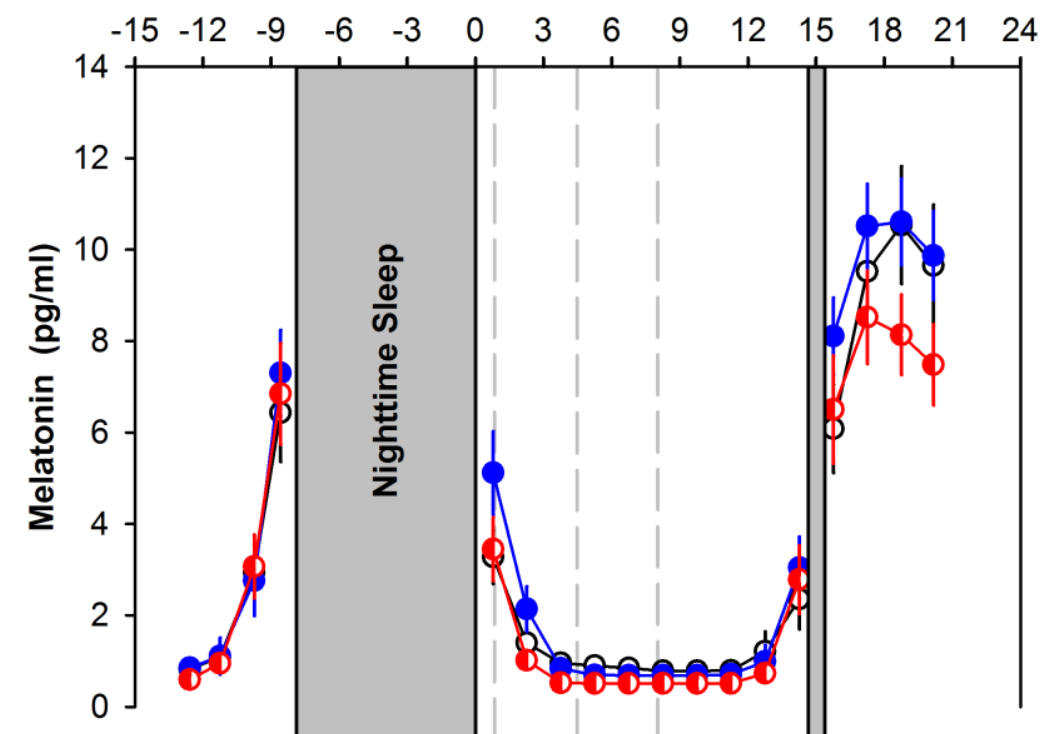

(b)

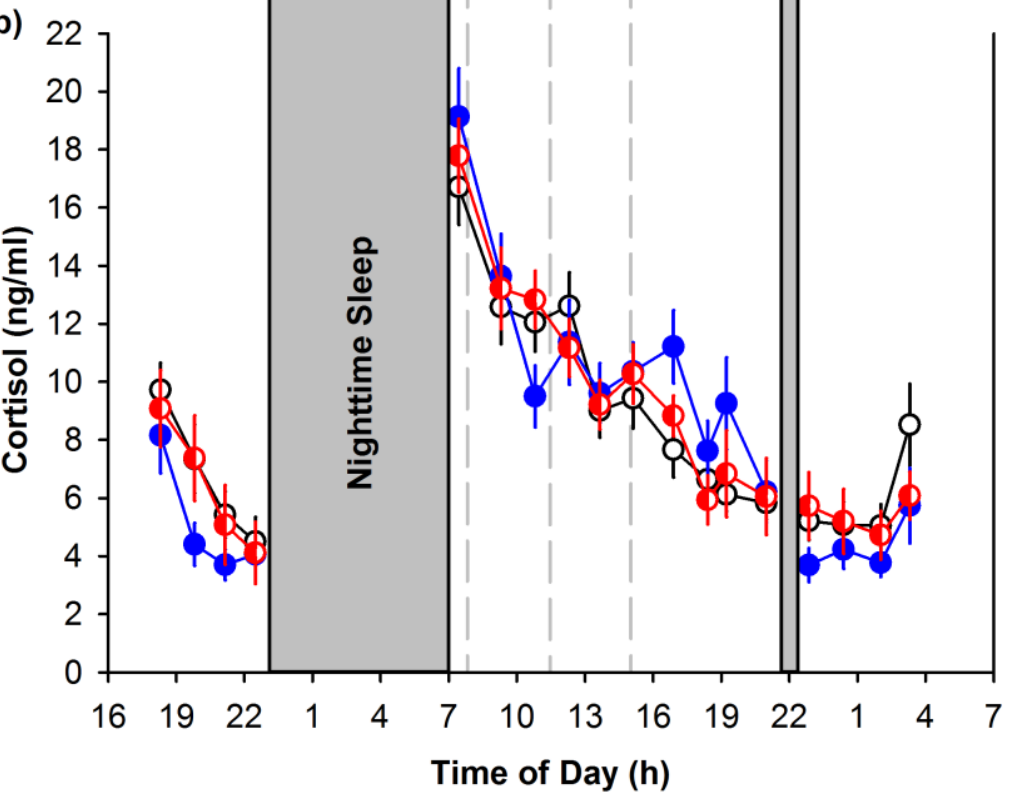


Figure 5
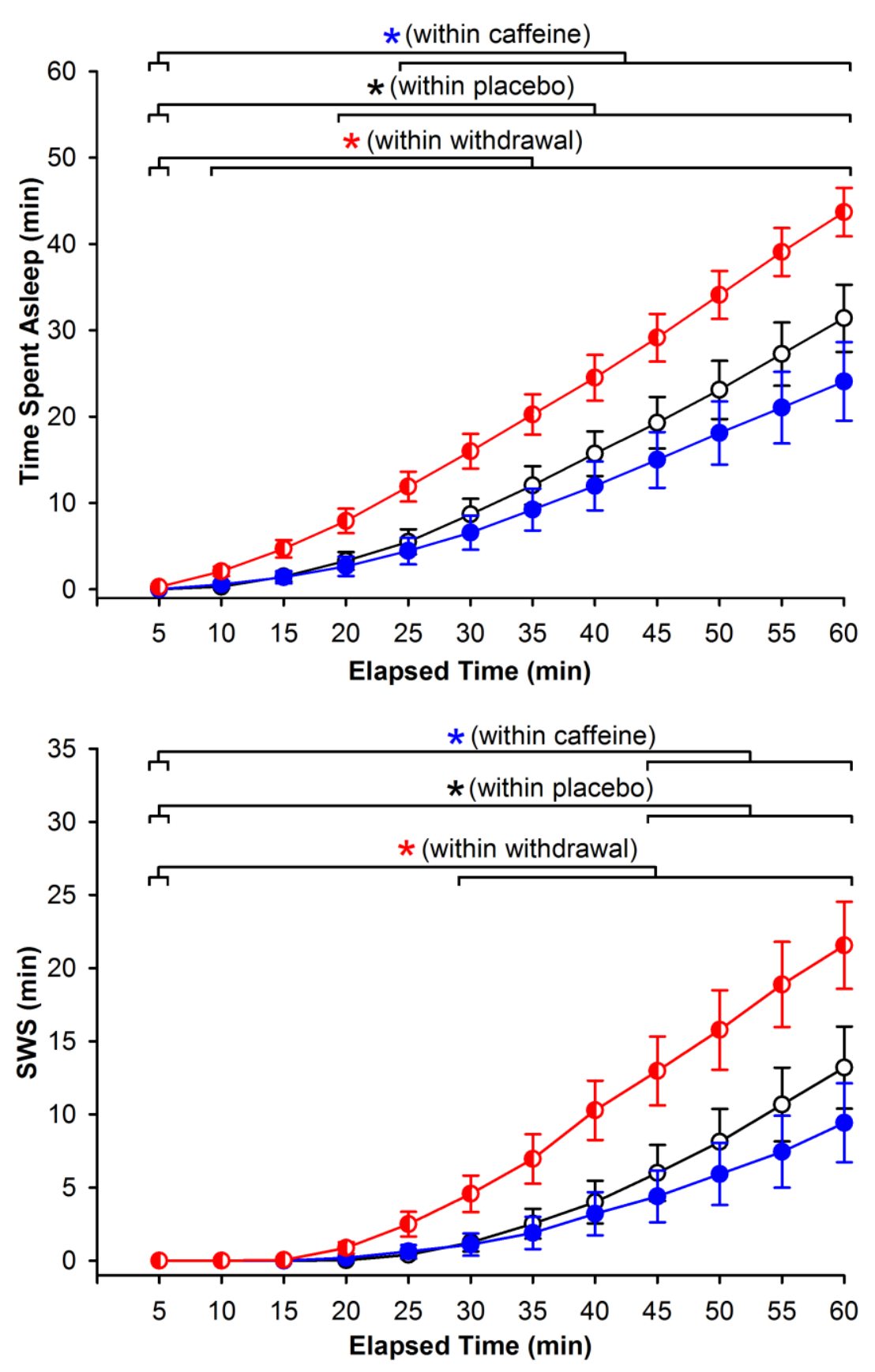


\section{Supplemental Material}

Description of study sample

Table S1. Demographic characteristics of study sample.

Table S1. Demographic characteristics of study sample.
\begin{tabular}{|lc|}
\hline Demographics & Mean \pm SD \\
\hline Age (years) & $26.4 \pm 4.0$ \\
Habitual daily caffeine intake $(\mathrm{mg})$ & $478.1 \pm 102.8$ \\
Body Mass Index (kg/m²) & $22.7 \pm 1.4$ \\
Morningness-Eveningness Questionnaire [1] & $52.8 \pm 8.7$ \\
Munich ChronoType Questionnaire (MSF sc) [2] & $4.2 \pm 0.7$ \\
Epworth Sleepiness Scale [3] & $3.6 \pm 3.4$ \\
Pittsburgh Sleep Quality Index [4] & $2.8 \pm 1.4$ \\
Beck Depression Inventory-II [5] & $1.4 \pm 2.3$ \\
\hline
\end{tabular}

\section{Timing of habitual daily caffeine intake}

As illustrated in the following table, caffeine was almost equally often consumed in the morning, during lunchtime and in the afternoon, which is similar to the timing of the caffeine administrations in the current study. Eight volunteers consumed caffeine additionally after dinner, however, mostly aliments containing low levels of caffeine such as soda drinks $(n=1)$, tea $(n=1)$, chocolate $(n=3)$ or cacao $(n$ $=1$ ). Only two volunteers consumed coffee after dinner. The information about the timing of caffeine intake of one volunteer was missing.

Table S2. Timing of at least one caffeinated beverage or food.

\begin{tabular}{|c|c|c|c|c|c|}
\hline Breakfast & $\begin{array}{c}\text { Between } \\
\text { Breakfast and } \\
\text { Lunch }\end{array}$ & Lunch & $\begin{array}{c}\text { Between } \\
\text { Lunch and } \\
\text { Dinner }\end{array}$ & Dinner & After Dinner \\
\hline$n=18$ & $n=17$ & $n=15$ & $n=18$ & $n=6$ & $n=8$ \\
\hline
\end{tabular}

\section{Rationale for sample size}

Calculation of sample size was done with G*Power 3.1 [6], planning the calculation of an ANOVA for repeated measures (three conditions) with an accepted $\alpha$ error probability $=0.05$ and power $(1-\beta)=$ 0.8. For an estimation regarding circadian phase, the assumed correlation between measures $(r=0.7)$ was based on a previous study, in which melatonin was assessed in two differential sleep pressure conditions in young healthy volunteers after seven days of a fixed sleep-wake cycle [7]. The expected 
effect size $\left(f^{2}=0.26\right)$ is assumed on the basis of [8] investigating the influence of caffeine on melatonin levels.

\section{Frequency of order of conditions}

Volunteers were pseudo-randomly allocated to the order of the three conditions based on random permutation controlling for block size.

Table S3. Number of participants per order of conditions.

\begin{tabular}{|c|c|c|c|c|c|}
\hline $\begin{array}{c}\text { Caffeine - } \\
\text { Placebo - } \\
\text { Withdrawal }\end{array}$ & $\begin{array}{c}\text { Caffeine - } \\
\text { Withdrawal - } \\
\text { Placebo }\end{array}$ & $\begin{array}{c}\text { Withdrawal - } \\
\text { Placebo - } \\
\text { Caffeine }\end{array}$ & $\begin{array}{c}\text { Withdrawal - } \\
\text { Caffeine - } \\
\text { Placebo }\end{array}$ & $\begin{array}{c}\text { Placebo - } \\
\text { Caffeine - } \\
\text { Withdrawal }\end{array}$ & $\begin{array}{c}\text { Placebo - } \\
\text { Withdrawal - } \\
\text { Caffeine }\end{array}$ \\
\hline$n=3$ & $n=3$ & $n=4$ & $n=3$ & $n=4$ & $n=3$ \\
\hline
\end{tabular}

\section{Caffeine levels during ambulatory phase}

In order to verify volunteers' compliance to the regimen prior to laboratory admission, samples containing fingertip sweat were collected approximately $8 \mathrm{~h}$ after the last pill intake on days one to eight and $5 \mathrm{~h}$ after the last pill intake on day nine of treatment. Subsequently, caffeine levels were analysed by triple-quadrupole mass spectrometry.

A significant main effect of condition $\left(F_{2,51.8}=21.70 ; p<0.0001\right)$ confirmed increased caffeine levels during the caffeine and withdrawal conditions compared to the placebo condition $\left(p_{\text {all }}<0.0001\right)$, depicted in Figure S1. Although these values suggest compliance, note that we cannot fully exclude that caffeine levels were due to the intake of caffeine-containing beverages and food rather than the treatment capsules. 


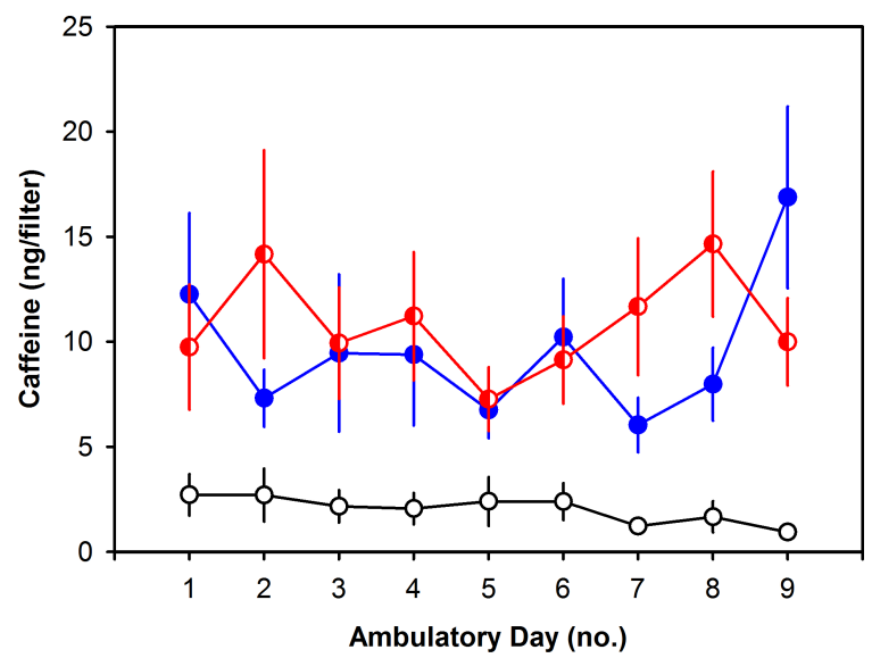

Figure S1. Time course of caffeine levels collected during the ambulatory phase in the placebo (black open circles), caffeine (blue circles) and withdrawal (red semi-filled circles) conditions confirming volunteers' compliance to the regimen.

\section{Handling and analyses of saliva samples}

Saliva samples were collected regularly in intervals of 30 to $60 \mathrm{~min}$ under dim light conditions (< 8 lux). Following collection, samples were stored at maximum $5^{\circ} \mathrm{C}$, later centrifuged (3000 rpm for a duration of $10 \mathrm{~min}$ ) and subsequently stored at $-24^{\circ} \mathrm{C}$ until data analyses. Melatonin and cortisol levels were analysed by a trained staff member (at Bühlmann Laboratories AG, Schönenbuch, Switzerland) using a direct double-antibody radio immunoassay [9] and an enzyme-linked immunosorbent assay (ALPCO, Salem, NH, USA), respectively.

To test caffeine-dependent shifts in circadian timing, we analysed condition-specific differences in dim light melatonin onset (DLMOnset) and dim light melatonin offset (DLMOffset). In order to account for slightly different bedtimes between conditions in three volunteers (twice: +30 min in caffeine compared to placebo and withdrawal conditions; once: -30 min in placebo compared to caffeine and withdrawal conditions), we further tested condition-specific effects in phase angle (difference of bedtime DLMOnset). However, phase angle did not significantly differ among the three conditions on day nine or on day ten of treatment $\left(p_{\text {all }}>0.2\right)$. A summary of melatonin parameters per condition and results of the statistical analyses are depicted in Table S4. 
Table S4. Melatonin parameters assessed on day 10 of treatment.

\begin{tabular}{|lrrrc|}
\hline Melatonin Parameter & \multicolumn{1}{c}{ Placebo } & \multicolumn{1}{c}{ Caffeine } & Withdrawal & Factor Condition \\
\hline DLMOnset $(\mathrm{h})$ & $21.74 \pm 0.33$ & $21.15 \pm 0.18$ & $21.60 \pm 0.31$ & $F(2,33.4)=1.16, p=0.325$ \\
Phase angle $(\mathrm{h})$ & $1.32 \pm 0.31$ & $1.91 \pm 0.16$ & $1.48 \pm 0.25$ & $F(2,33.6)=1.46, p=0.246$ \\
DLMOffset $(\mathrm{h})$ & $8.35 \pm 0.45$ & $9.04 \pm 0.26$ & $8.69 \pm 0.22$ & $F(2,35.3)=1.32, p=0.280$ \\
Amplitude $(\mathrm{pg} / \mathrm{ml})$ & $11.00 \pm 1.44$ & $10.71 \pm 1.02$ & $9.92 \pm 1.32$ & $F(2,33.8)=0.57, p=0.573$ \\
AUC $\left(\mathrm{pg}^{*} \mathrm{~h} /\left(24^{*} \mathrm{ml}\right)\right)$ & $3.17 \pm 0.36$ & $3.78 \pm 0.41$ & $2.96 \pm 0.39$ & $F(2,33.8)=1.77, p=0.185$ \\
\hline
\end{tabular}

DLMOnset: dim light melatonin onset; DLMOffset: dim light melatonin offset; AUC: area under the curve. Values represent means \pm standard errors for each condition.

For a more detailed inspection, the individual values of the DLMOnset, DLMOffset and the amplitude on day 10 of treatment are presented in Figure S2.
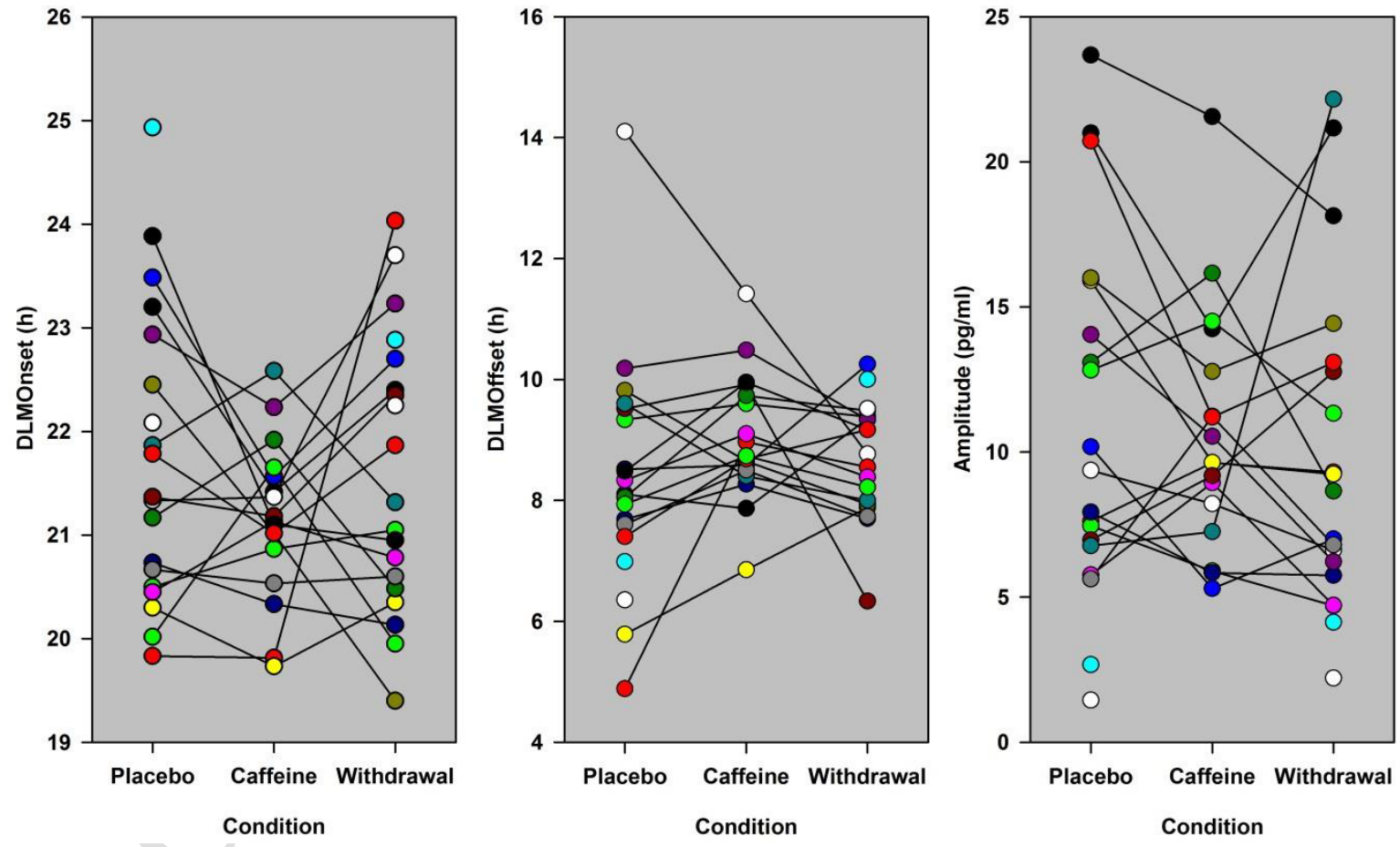

Figure S2. Depicted are the individual values for the melatonin parameters DLMOnset (left), DLMOffset (centre) and amplitude (right) assessed on day 10 of treatment. The exclusion of a visually identified extreme value (> $1.5 \mathrm{x}$ interquartile range) in the analyses of DLMOffset (depicted as white point in the figure) reveals a significant delay in the caffeine condition compared to placebo (main effect of condition: $F_{2,34.5}=3.75 ; p=0.034$; post-hoc tests: $p=0.030$ ). 


\section{Polysomnographic recordings}

For recordings, we used a portable V-Amp device (Brain Products $\mathrm{GmbH}$, Gilching, Germany) and Grass gold cup electrodes. Applied according to the standard international 10-20 system, two electrooculargraphic, two electro-myographic and two electro-cardiographic signals were recorded, together with six derivations from the frontal, central and occipital regions (F3, F4, C3, C4, O1, O2) referenced against the linked mastoids (A1, A2). Data were recorded with a sampling rate of $500 \mathrm{~Hz}$ and filtered online by applying a notch filter at $50 \mathrm{~Hz}$.

Epochs of 30 seconds were visually scored. Additionally, one third of the data have been scored by a second trained staff member in order to ensure a continuous scoring agreement of at least $85 \%$. 


\section{References}

1 Horne JA, Ostberg O. A self-assessment questionnaire to determine morningnesseveningness in human circadian rhythms. Int J Chronobiol. 1976;4(2):97-110.

2 Roenneberg T, Wirz-Justice A, Merrow M. Life between clocks: Daily temporal patterns of human chronotypes. J Biol Rhythm. 2003;18(1):80-90.

3 Johns MW. A new method for measuring daytime sleepiness: the Epworth sleepiness scale. Sleep. 1991;14(6):540-5.

4 Buysse DJ, Reynolds CF, 3rd, Monk TH, Berman SR, Kupfer DJ. The Pittsburgh Sleep Quality Index: a new instrument for psychiatric practice and research. Psychiatry Res. 1989;28(2):193-213.

5 Beck AT, Steer RA, Brown GK. BDI-II, Beck depression inventory: manual. Boston: Harcourt Brace. 1996.

6 Faul F, Erdfelder E, Buchner A, Lang AG. Statistical power analyses using G*Power 3.1: Tests for correlation and regression analyses. Behav Res Methods. 2009;41(4):1149-60.

7 Reichert CF, Maire M, Gabel V, Viola AU, Kolodyazhniy V, Strobel W, et al. Insights into behavioral vulnerability to differential sleep pressure and circadian phase from a functional ADA polymorphism. J Biol Rhythms. 2014;29(2):119-30.

8 Wright KP, Jr., Badia P, Myers BL, Plenzler SC, Hakel M. Caffeine and light effects on nighttime melatonin and temperature levels in sleep-deprived humans. Brain Res. 1997;747(1):78-84.

9 Weber JM, Schwander JC, Unger I, Meier D. A direct ultrasensitive RIA for the determination of melatonin in human saliva: comparison with serum levels. J Sleep Res. 1997;26:757. 